Discourse and Communication for Sustainable Education, vol. 7, no. 1, pp. 125-138, 2016

\title{
The Spiritual Dimension of Education - Addressing Issues of Identity and Belonging
}

\author{
Marian de Souza \\ Australian Catholic University, Australia
}

\begin{abstract}
In a shrinking world where events across the globe become relevant for the lives of masses of people regardless of the distances that divide them, some serious issues have arisen which have particular significance for education policies and practice. Too many children are growing up against a backdrop of polarised views and attitudes which is a cause for concern in many countries where societies are characterized by racial, cultural and religious diversity.

This article explores some critical concepts that are pertinent to contemporary Australia and uses research findings and content analysis to problematize the issue. It argues that there is clear evidence that the health and wellbeing of children and young people is being affected by exposure to prejudicial attitudes which can be linked to the diversity that has become a sustaining feature of many contemporary societies and it has had serious consequences for their identity and sense of belonging. It proposes that one way of addressing these issues is through education that addresses the relational dimension of students' lives which is expressed through their connectedness to all others, that is, their spiritual natures. Finally, it identifies some features of such an educational system.
\end{abstract}

Keywords: globalization, plurality, connectedness, spiritual wellbeing, radicalization, Islamophobia, non-conscious learning, prejudice

The $21^{\text {st }}$ century has witnessed the world becoming increasingly polarised. At one end, progress in the various shapes and sizes of science and technological invention, economic and political stability and greater access to education and health care are symbols that suggest social and emotional wellbeing for the many but, in relative terms across the globe, often only benefit the few. At the other end, there is the turmoil and desperation of millions of displaced people and the substantial problems for western countries, which have wealthy democratically elected governments, to somehow manage the impossible numbers of asylum seekers alongside the heightened security required to combat the threat of terrorism. Such polarisation is readily communicated to large numbers of people across the world precisely because media technology and social networking has made the world a much smaller place where events that occur in one 
region can have repercussions in far distant places including on the other side of the globe.

Within the context of these global affairs, there are issues that should be of particular concern for educators, issues that affect the everyday lives of many children and young people. They are growing up amidst the horror stories and images of other children and young people affected by wars and natural disasters, of the dire warnings of global warming and the destruction of their planet, of the intimidation of terror attacks, and most importantly, the fear of those who are different that is inspired in them by the rhetoric of media and public authoritative voices within their communities. It is little wonder, then, that across the western world there is a growing number of children and young people suffering from anxiety, tension and associated mental health problems (for instance, see Claxton, 2008; de Souza, 2016; Mission Australia 2014).

For this article, I will focus on one of these issues that impact on the wellbeing of children and young people - the fear of the Other ${ }^{1}$ who is different. In a world where social, cultural and religious diversity has become a sustaining feature of most countries, the fear of the different Other and the corresponding actions instigated by such fear, creates significant problems for social cohesion as well as emotional, physical and, indeed, spiritual wellbeing of both, individuals and their communities. As such, it is imperative that ways and means are devised in order to address this issue and, I would suggest, that education is one avenue where this can take place.

\section{A Concept of Spirituality in Education}

My research for the past twenty years has examined the role of spirituality in education in terms of nurturing the relational aspects of students' lives, thereby promoting experiences of connectedness (see de Souza, 2003, 2004, 2006, 2009, 2013, 2014, 2016). The author have identified how the spiritual dimension of learning contributes to mental, emotional and physical wellbeing and, potentially, to the nurturing of socially cohesive communities $(2009,2013,2014,2016)$. The author have also argued that the spiritual dimension of western education was seriously neglected in the previous century for a variety of reasons (de Souza, 2006, 2016). For instance, there was a concentration on cognitive learning to provide students with knowledge and skills for the workforce in the twentieth century. As well, there was a commonly held perception in the western world that spirituality pertained to religious life and, therefore, was the prerogative of those belonging to a faith tradition. Such thinking firmly placed spirituality in the personal realm of individual and communal life.

There has been a range of multidisciplinary research ${ }^{2}$ over the past decade into contemporary understandings of spirituality which is an indication of the spread and seriousness of the research into spirituality. Most of this has recognized the obvious religious links but, at the same time, has identified spirituality as a separate entity. As well, they have recognized spirituality as an essential element of the human person. The

\footnotetext{
${ }^{1}$ I use Other as a collective noun for all others who are not the Self.

2 See de Souza, Bone \& Watson, in press for 2016 where this concept is described in writings across religious, secular, health, psychological, neuroscience, social/cultural and educational perspectives.
} 
author would suggest, then, that it is necessary at this point in the history of human learning to recognize and amend the current situation in education that, generally, continues to ignore the spiritual dimension of students' lives and their learning. Accordingly, the author will first briefly revisit contemporary concepts of spirituality to show that, if we are to develop a sustainable education system which will prepare students for the world in which they are growing into, it is important to identify and address the spiritual dimension. The author will then examine a particular scenario from Australia that highlights the impact on young people who appear to have lost their sense of belonging and identity both, within their own religious and cultural communities and within the wider society in which they live. Such experiences, potentially, have led to them becoming spiritually impoverished and disenfranchised. Finally, I will offer some suggestions as to how we may address the corresponding issues by nurturing spirituality in education.

The findings of my own early research (de Souza, 2003, de Souza, Cartwright \& McGilp, 2004) which supported and, in turn, which have been affirmed by others (for instance, Culliford, 2011; Fisher, 2010; Hay, 2006; Hay \& Nye, 1998; Hyde, 2008; among others), clearly indicated that spirituality is an innate element in the human person, implicit in the relational dimension of life. In brief, the individual feels a deepseated connection to the Other. For some, this connectedness is grounded in the human world but for others, it stretches beyond to a non-human world where they may encounter a transcendent reality, which brings the experience of oneness; that is, being a part of the whole (see for instance, Armstrong, 2009; Gilbert, 2009; Newberg, D’Aquili, \& Rause, 2001).

This understanding of the human experience of oneness and unity may be found across a variety of disciplines where spirituality has been the subject of research ${ }^{3}$. Different belief systems have various names for such experiences. In some religions, for instance, it has been personified into a God, male and/or female. Nonetheless, in its essence, it is a concept about Absolute Reality, Ultimate Unity or the Divine Mystery.

The connectedness that may be seen in an individual's response to Other is reflected in levels of empathy the individual experiences towards Other and may be expressed through joy, happiness, peace, justice, freedom, liberation, awe, wonder, wisdom, compassion and so on. Spiritual growth occurs when positive experiences of connectedness are nurtured. In her discussion on a concept of 'village life', Pinker (2014), stresses the importance of face-to-face contact as against the experience of being 'alone together' (Turkle, 2011) or the 'distant connectedness' (de Souza, 2009, 2016) that is the characteristic of relationships forged and maintained on the internet or through social networking explains why the experience of close physical connectedness is vital to human wellbeing. She says, 'long -term bonds are forged through a casual exchange of homebaked goods, baby-sitting, borrowed tools, shared expertise and spur-of-the-moment visits' (p. 74). In other words, people help each other and do things for each other not just to get a job out of the way but to affirm their relationships and ties to one another. Citing Arlie Russell Hochschild's research, Pinker points to the fact that the bonds formed amongst neighbours and members of a community indicated an unspoken pact, that if anyone was ever in need, others in their community would be there for them. She concludes, 'villagers might quarrel, gossip, get bored, and leave. But living there, they paid a moral tax to the community in this readiness to 'just do' (p. 74).

\footnotetext{
${ }^{3}$ See Footnote 2.
} 
This idea supports my own thinking when I have argued that a sense of belonging to a group provides a person with their sense of self and place which, in turn, inspires in them a sense of purpose as they see themselves as having some responsibility to and for their group. As well, it offers them a framework of meaning within which they may be able to understand and/or interpret their everyday experiences (de Souza 2003, 2004, 2012a, 2014, 2016).

Negative experiences of connectedness which reflect the shadow side of spirituality are instances when the individual becomes displaced, alienated, self-harming and so on (de Souza, 2012b, 2016). Thus, the aim for educators and other professionals who work with children and young people should include the promotion of positive experiences of connectedness which will enhance the individual's sense of belonging and wellbeing as well as reduce negative experiences which lead to disconnectedness (de Souza, 2012b, 2016). As I have discussed elsewhere (de Souza, 2006, 2008, 2016), western education systems which have influenced learning in both Western and Eastern countries are driven by a scientific world view that is objective, positivistic and reductionistic, focusing as they do on compartmentalization, competitiveness and the promotion of the individual over the group (for instance, Claxton, 2008; Lucas \& Claxton, 2010; Moffett, 1994; Noddings, 1992; Robinson, 2001; Robinson \& Aronica, 2009, among others). What such a system has failed to recognize is the holistic nature of learning which is grounded in the totality of human experience, that is, one which integrates rationality, emotionality, physicality and spirituality (for instance, see de Souza, 2016; hooks, 1994; Miller, 2000, 2006; Miller \& Nakagawa, 2001). As has been acknowledged by many, In such a system, it is predictable that some students will rarely, if ever, experience success. Moreover, when their individual gifts and talents do not coincide with the subject areas that are weighted as important, they may also experience a de-valuing of self so that they reject a part of themselves and retreat from the reality of their daily lives into a virtual world or into alienation and isolation (Claxton, 2008; de Souza, 2016; Robinson \& Aronica, 2009). These are very real problems across many education systems in today's world and the issues and challenges associated with the diversity linked to the spread of different academic strengths and abilities is being compounded by the cultural and religious diversity that has become the norm in many societies.

Thus, with the understanding of spirituality as pertaining to the relational dimension of being with corresponding expressions of connectedness to Other, combined with the recognition that religious and cultural diversity characterizes many societies today, I would like to examine these issues and the relevance they have for the radicalization of young Australian Muslims. While these problems have occurred in other countries, I shall restrict this discussion to the Australian situation.

\section{Some Issues Related to Diversity - Racial, Cultural and Religious}

In the early years of the last decade following 9/11, there was a rapid rise in religious fundamentalism in this country, expressed as Islamophobia (Pratt, 2015). Pratt states that religious fundamentalism, such as Islamophobia, has exclusivist attitudes (p. 210) where the otherness of Other is not only rejected but can lead to acts of decimation. As a result, Muslims who had lived and settled peacefully in Australia for many years, suddenly found themselves on the outside of mainstream society. This, especially for 
children and young people, impacted adversely on their sense of their home country and the wider community that had previously provided them with a sense of belonging. Suddenly, in a short space of time they were facing hostility and rejection, thereby leading them to experience a degree of marginalization. The media coverage of politicians and other strident voices were complicit in creating a concept that 'all Muslims were terrorists' and that 'we did not want people like that here'. This latter claim was triggered by the regular arrival of boats containing asylum seekers on Australia's north-west shores, most of whom were fleeing from the devastation of their homelands which were largely Muslim. Thus, the fear of the different Other was being blatantly propagated by the country's leaders and inevitably, this triggered incidents of prejudicial attitudes to particular communities which, initially, were identified by their religion and culture but which, subsequently, created racial tensions.

A particular incident relevant to racist attitudes occurred in 2014 when, in a statement to the Australian Parliament, the Governor General upheld the right of a Right Wing columnist to free speech even if it set out to be deliberately offensive to others. His statement that 'Everyone has a right to be a bigot' went viral. The immediate response by a large number of Australians was to decry such an attitude. Some acknowledged that it is usually a 'white' dominant individual who is the proposer of such ideas (Ali, 2014) and that, as a rule, white people are the only ones who are not identified by their race (Ali, 2014). While Ali's (2014) statement was specific to the Australian situation, it is quite possible that his perceptions are shared by other non-white people in other societies that are characterized by racial diversity and ethnic minorities.

As I have written elsewhere (de Souza 2012a, 2016), the 300+ history of colonialism in our recent past has, no doubt, impacted on the non-conscious learning of everyone, so even if one's conscious mind directs one's actions in terms of racist attitudes and behaviours, and allows one to see oneself as a liberal, inclusive and politically correct person, one's non-conscious learning has been seared by 300 years of cultural history, stories, images and the superior attitudes of white people towards people of every other colour in every kind of way - culture, intelligence, religion and so on. And, if we do not acknowledge our non-conscious learning, it continues to affect the way we perceive and behave in the world, although its influence is subtler and not always recognizable, and therefore, can be much more insidious. This is true for all people regardless of the colour of their skin so that their attitudes and behaviour towards people who do not share their skin colour may be 'coloured' by their non-conscious perceptions. These are, indeed, serious issues in societies characterized by plurality and they need to be acknowledged and addressed in sustainable education systems so that both teachers and students are encouraged to recognize any prejudices they feel which are possibly being driven by their non-conscious learning (de Souza, 2009, 2016, Myers, 2002; Wilson, 2002).

In more recent times, young people have grown through their most vulnerable years against a backdrop of prejudicial attitudes and Islamophobia. It is not surprising, then, that attitudes and actions of fear and discrimination which have become a visible symptom amongst many of our young people are a direct result of their non-conscious learning.

I have also argued that Helms' (1993) concept of cultural racism which suggests that some cultures see their own as being infinitely superior to others may be extended to include a concept of religious racism where an assumption about the superiority of 
one's own religious beliefs and practices leads to attitudes that marginalize others (de Souza, 2016). I believe this is very relevant to many multi-faith societies today where some individuals or communities may become recipients of such attitudes, especially on their home soil. Such experiences are likely to be disturbing enough to impact on their sense of identity and belonging which could then be a contributing factor in the shaping of their understandings and expressions of their spiritual selves.

In addition, when diversity is implicit in the fabric of society, there is more potential for a rise in prejudicial attitudes based on racial, cultural and religious difference and, as has happened in the western world since 9/11 and the subsequent terror attacks directed towards western countries, this can be intensified when politics are involved. Das (2012) clearly captures the impact on the mental, emotional and spiritual wellbeing of individuals who experiences hostility because of their race in the following excerpt:

Racism, in all its overt and insidious ways, has the capacity to sear its mark on a person - you look back at the wound and realize it's bigger and uglier than you thought. Delayed trauma seeps into your heart and hardens it ever so slightly - It is just a big solid lump that you carry around in your rucksack for the rest of your life (p. 63).

Many young people in Australia and elsewhere have grown up against this backdrop of cultural and religious racism. From their earliest years they have witnessed images and news reports that have combined terrorism with Islam. For young Australians who are not Muslim the constant exposure to such messages is very likely to promote negative perceptions about Muslims. As well, it is likely that they will develop, consciously and non-consciously, a collective fear and aversion towards such a group. Such feelings and attitudes will cause tension and friction which can affect their sense of connectedness to Other and therefore, their spiritual wellbeing. On the other side, for young Muslims such negativity is likely to be experienced as a distinct attack on their religious identity. They suddenly realize that the safety that accompanies a sense of belonging is being denied them in their homeland. Tsioilkas (2008) illustrates this well when he says:

Those of us who do not fear deportation, starvation, the knock on the door from the police or the immigration officer, are going to experience liberation and opportunity differently to someone living in fear... it is equally ridiculous to maintain that we all have an equal relationship to the state (p. 23).

It is more than probable that these young people find themselves in a state of confusion and bewilderment because their national identity is in conflict with their religious identity (Erricker, 2008). The ensuing problem is that it triggers in them a sense of displacement as they try to come to terms with their new situation (Roy, 2004; Das, 2005, 2012). Pratt (2015) argues that the extremist attitude which has led to Islamophobia, may be seen as instrumental in provoking disaffected young Muslims in many western countries to search for a community which apparently shares their ideals and values and to which they feel a sense of belonging and connectedness. Roy's (2004) contention about the birth of a global form of Islam and the search for a new Ummah augments this argument.

In migrant countries such as Australia, many new arrivals experience a mental, emotional and physical distance from their countries of origin. With first generations this often means that, in their attempt to keep their religious and cultural values alive so 
as to hand on to their children, they become firmly grounded in the religious culture they brought with them. As a result, while the culture will change over time in their original countries, in the new country it remains in a time warp. With second generations, however, their religious and cultural values begin to adapt to their new surrounding and with the ensuing acculturation process, they develop a new religious identity, which no longer feels comfortable with the traditional religious identity of their parents (Erricker, 2008; Roy, 2004). Thus, the younger generations may have a more fluid religious identity. Pertinent to this discussion is Bauman's (2004) notion of liquid identity which suggests that individuals' identity may shift from one facet to another in response to shifting circumstances - that is, they develop multiple identities. One outcome is that they are not as firmly grounded in any one identity as their parents and grandparents may have been. Identity may be formed by a deep sense of self which grows out of the bonds that reflect the belonging to and acceptance by one's community and this contributes to the spiritual wellbeing of a child or young person. When this identity is suddenly threatened, it can be quite shattering, especially to young people as they are trying to establish themselves in the world. It can have a detrimental effect on their self-esteem as well as their self-confidence and ultimately, their spiritual wellbeing. Unfortunately, for many young people, their way of being in the world has been affected by hostile and prejudicial attitudes precisely because of the indefiniteness implicit in multiple identities.

On all sides, then, when the essence of a society is diversity where prejudicial attitudes continue to exist towards one or another group that makes up that society, social cohesion and communal wellbeing will not be achieved. To address such problems, we need to turn our attention to ways of promoting connectedness amongst our children and young people. We need to develop programs that nurture their relational selves and, therefore, their spirituality. In other words, a sustainable education system needs to recognize and address the whole child as a rational, emotional and spiritual being. The number of terrorist attacks in recent times has intensified the fear of others who are different and are a clear indication of the urgency that is needed to develop programs that will bring to all children and young people a valuing of self and all others and learning to live with all others with respect and dignity where each child is provided with a context in which s/he can develop their potential to grow into active, empathetic and compassionate citizens. I argue that this may be achieved if we develop a holistic learning program where the whole child is recognized as a rational, emotional and spiritual being, and where learning environments and activities are designed to teach children to see themselves as part of the whole, where the gifts of others complement their own and all are equally viable, valuable and essential for a community to function effectively and contribute to the wellbeing of each and every individual. Developing a holistic approach to learning will provide the basic foundation for such programs.

\section{Sustainable Education for the Twenty-First Century}

Australian education has witnessed the development of any number of new or reviewed curricula over the past thirty or forty years. This has happened in other countries as well and suggest that, despite distinct claims each time that the new curriculum will address or even eradicate existing problems, in fact, the call for renewals a few years later clearly indicate that we need a complete overhaul of the current system instead of 
the 'band-aid' approach that we continue to apply in an effort to resolve existing problems. This is reflected in Brunold's (2015) discussion on the concept of global learning. He pointed out that current knowledge about the environment and about human use of nature and ecosystems will become outdated very quickly so that 'applying such outdated knowledge may even be considered to be harmful' (p. 37). Consequently, he argues that teaching about the environment must be accompanied by 'a sense of relativity and uncertainty about the future' which is quite incompatible with current approaches to learning. Ultimately, Brunold identifies the necessity 'to rethink and redefine learning, a process that is determined by challenging knowledge that seems to be indisputable' (p. 37).

A further perspective on global learning is offered by Iliško, Skrinda \& Mičule (2014) when they contend that

each student lives within the interconnected framework of political, cultural, economic and ecological dimensions that influence them in significant ways. Each student is imbedded (located) within a particular culture with its specific heroes, series and meanings. The meaning each person makes is both deeply collective and personal. Therefore, each student creates his/her personal future vision and his/her personal meaning (p. 90)

Accordingly, Iliško et al (2014) assert that 'future schools need to equip students with necessary skills and competencies to live in an increasingly globalised world and to understand the unique contribution each of them can offer' (p, 89). As they recognize, it is our students of today who will be the decision makers and workers of the future and who will, therefore, 'play a significant role in facilitating sustainable development to 2 better meet future challenges (p. 89)

There have been other calls for such overhauls for many decades (for instance, Lucas \& Claxton, 2010; Claxton 2008; Illich, 1970; Freire, 1970; hooks, 1994; Miller, 2000, 2006; Noddings, 1992; and Robinson 2001, among others) and one thing they have in common is the recognition that the current system was designed for a previous century. It is outdated and can no longer adequately provide for and prepare young people for their future worlds. In order to address this situation, I recently wrote that:

A starting point would be to begin by recognizing that the child is a multidimensional being; an individual with a rational mind that thinks, an emotional mind that feels and a spiritual mind that intuits, imagines, wonders and creates. And this multidimensional mind is encased in the physical body which allows the individual child to engage, mediate and interact with the world around them through their perceptions and senses. Thus, if we accept that the child is a rational, emotional and spiritual individual, we need to question why education has traditionally only catered for the first of these qualities in core programs (de Souza, 2016, p. 123).

I have argued that learning programs should recognize the complementarity of cognitive, affective and spiritual learning. As well, the physicality of the child means that multi-sensory learning should be identified and addressed. A framework for such learning is based on the concept that three categories of intelligence, intellectual, emotional and spiritual provide a well-rounded understanding of human intelligence with corresponding processes: perceiving/sensing, thinking, feeling, intuiting/imagining/ 
creating and/or problem solving. The interaction and integration of this process is holistic and involves multisensory learning which, because it engages the whole child, has the potential to be transformational.

For too long, some disciplinary subjects have been deemed as more important than others which immediately creates a situation where one child's ability is more valued than another because their particular gifts, talents and skills belong in such disciplines. Such perceptions are usually generated by the requirements of business and industry. In other words, education has, for over a century, been seen as a means to prepare students for the workforce. However, the twenty-first century has brought about significant changes to the workforce, so that many traditional jobs have disappeared and many future jobs are yet unknown. It is almost nonsensical, then, to continue our current practices which are based on the premise that the main goal of education is to prepare children for the future world of work. Instead, a more appropriate goal would be to assist children to nurture the relational dimension of children's lives to help them realize their own potential as well as that of others so that they will learn to engage fruitfully with others. Further, they need to know how to develop and draw on their inner strengths to engage with the prospects and challenges that they will face through the different stages and aspects of their lives, not just in the workplace.

The multi-sensory nature of learning means that individuals mediate with their external environment through all of their senses but that each sense provides a different aspect or slant on the information that is taken in. This is one of the reasons why using the arts to promote learning in different disciplies can be effective as it creates different avenues to connect with the student. The arts can trigger a variety of thoughts and feelings in the learner, depending on their previous experiences and backgrounds. These new thoughts may further illuminate the students' perceptions of the familiar, or transform their vision of the world. Such an approach can inspire in students a sense of mystery, magic and wonder, and possibly a glimpse of something beyond the mundane reality of their everyday - in other words, it has the potential to tap into the students' ability to imagine and create. As Einstein said:

Imagination is more important than knowledge. For knowledge is limited to all we now know and understand, while imagination embraces the entire world, and all there ever will be to know and understand (retrieved from http://quoteinvestigator.com/2013/01/01/einstein-imagination/. April. $4^{\text {th }}$, 2016)

Given the variety of abilities and backgrounds that may be found in any group of students, each will enter into the learning process at different vantage points. This suggests that when a class is divided into small working groups with enough time for students to reflect on new information, share their reflections, listen and discuss the new information with others, there is a greater chance that the connections established between the students during the learning process will increase their skill at responding both individually and collectively to the content of the lesson. Potentially, this should lead to deeper engagement with and understanding of the topic. Such a process should also increase their understanding of their relationship to the group whereby they learn that a collective response should be made up of individual voices and that they have the opportunity to be an individual voice with the potential to shape the whole. 
My extensive experiences of teaching classroom music, drama and English in secondary schools over a twenty-five-year period provided me with these insights about how the arts can extend learning and inspire creative responses in all students regardless of their ability. As well, my students learnt that being part of a performance group mean that every individual was equally important to the performance. Each had a part to play to contribute to the whole. Each voice was valued and while some may have been more gifted than others or had a more prominent role in one performance, there was always the next performance which would provide the opportunity for someone else to lead. They understood that the ultimate performance was dependent on each person playing their specific roles to the best of their ability.

The process required every group member to listen to each other, respond to the needs of each other, ask for help if and when they needed it, take on responsibilities that would ensure the wellbeing of the group, and to speak out if they felt they had something important to say. This is the kind of learning that helps a child to grow into a wellrounded adult who can contribute meaningfully to the wellbeing of the group.

These are some of the important features of arts-based learning. Unfortunately, the arts are one of the discipline areas that are undervalued in education since the benefits they offer are often intangible and do not obviously lead to explicit material gain. However, when attempting to address the emotional and spiritual dimensions of education, the arts are an invaluable resource and medium. They are an expression of the inner self/spirit and they provoke a response from the inner self/spirit of the receiver, hence, they can be viewed as the unconscious language of the soul of humanity which transcends racial, cultural and religious boundaries.

\section{Conclusion}

To bring this discussion to a close, a new education system that is relevant for the contemporary world will change its focus and character so that it will be:

Multidimensional and involve a process that allows each child to draw on his/her individual gifts, abilities and resources, whatever they are, so as to reach his/her potential to become a well-rounded, whole person. This means that resources and activities will be designed to promote learning in ways that all children can engage in. They will be able to draw on their own skills and understandings to access the learning. They will not be discriminated against because their individual gifts and backgrounds don't conform to particular expectations.

Equip each child to engage positively with the world in all aspects of his/her life as each of them experiences it. Thus, each child will learn to see every other child as a vital element of the whole community, each with an important part to play so that respect for and valuing of other becomes a natural expression of all children. It also involves the need for children to learn about how the wider community operates and how each of them have a responsibility to contribute to the wellbeing of the wider community because their own wellbeing is dependent on this. Certainly, this is an aim that is particularly challenging in the face of the diversity and the fear of difference that exists in so many societies today.

Develop innate strengths and capabilities that will empower each child to make effective and beneficial contributions to the wellbeing of future communities which, in turn, will promote their own sense of self, place and wellbeing. Accordingly, the meaningful 
contribution that different subjects bring to each child in their growth into adulthood will be acknowledged - these include the traditional 'important' subjects like language, maths and science as well as the humanities, social sciences, the arts, and technical and physical education. Each discipline brings a different way of knowing - cognitively, affectively and spiritually. As well, opportunities will be included for multi-sensory learning which can enhance knowledge and understanding but which require more time for learning to take place, for instance, when non-conscious learning such as intuitive, imaginative and creative processes come into play. Therefore, school days need to be restructured to allow for holistic learning that is inspired by the integration and complementary nature of different subjects and different abilities.

Finally, teachers and children need to recognize the impact that their conscious and non-conscious learning may have on their attitudes and behaviour. This is an aspect that should also be introduced into teacher training programs as it is an essential component in programs that seek to promote an understanding of different beliefs and worldviews as a step towards becoming more inclusive of and empathetic with and compassionate for the Other.

Apart from the outmoded education system that is on offer for students today, there is also the complexity of the politics of a global plural world which contextualizes their learning programs and environments. These issues have enormous significance for the current and future lives of school-aged children in terms of their identity and sense of belonging. If we, indeed, desire that our children and young people can live healthy and prosperous lives with inspired visions for their own future worlds we need to act now to identify and address the spiritual dimension of education. We need to create ways whereby we can nurture the connectedness that every human person needs in order to grow into inclusive, concerned, empathetic adults who, in turn, can create compassionate communities of peace, harmony and wellbeing. In a world besieged by political greed and materialistic values, this should be the ultimate goal for a sustainable education system that aims to prepare children for the global world of the twenty-first century.

\section{References}

Ali, W. (2014). Brandis' race hate laws are whiter than white. The Age, March 27, 2014. Retrieved on April 14, 2014, from http://www.theage.com.au/comment/ brandis-race-hate-laws-are-whiter-than-white-20140327-35lv7.html\#ixzz2xb NuPmu5

Armstrong, K. (2009). The case for God: What religion really means. London: The Bodley Head.

Bauman, Z. (2004). Identity. Cambridge, UK: Polity Press.

Brunold. A. (2015) Civic education for sustainable development and its consequences for German civic education didactics and curricula of higher education. Discourse and Communication for Sustainable Education, 6, 30 - 49. DOI: 10.1515/dcse2015-0003

Claxton, G. (2008). What's the point of school? Rediscovering the heart of education. Oxford: Oneworld Publications.

Culliford, L. (2011). The psychology of spirituality: An introduction. London and Philadelphia: Jessica Kingsley Publishers.

Das, S. (2012). Deranged marriage: A memoir. North Sydney, Australia: Bantam Books. 
Das, S. (2005). Between two worlds. The Age. $28^{\text {th }}$ July, 2005. Retrieved $28^{\text {th }}$ July, 2006, from http:/www.theage.com.au/news/sushi-das/between-two-lworlds/2005/ 07/27/1122143904716.html

de Souza, M. (2016). Spirituality in education in a global pluralised world. London and New York: Routledge.

de Souza, M. (2014). The empathetic mind: The essence of human spirituality. International Journal of children's Spirituality 19(1), pp. $45-54$.

de Souza, M (2012a). The dual roles of unconscious learning in engendering and hindering spiritual growth: Implications for religious education in pluralist contexts. In Jeff Astley \& Leslie Francis (Eds). Teaching religion, teaching truth, (pp. 184-203). Bern, Switzerland: Peter Lang AG International Academic Publishers.

de Souza, M. (2012b). Connectedness and connectedness. The dark side of spirituality: Implications for education. International Journal of children's Spirituality 17(3), 291-304.

de Souza, M. (2009). The spiritual dimension in educational programs and environments to promote holistic learning and wellbeing: An introduction. In M. de Souza, L. Francis, J. O'Higgins-Norman, \& D. Scott, (Eds). International handbook of education for spirituality, care and wellbeing (pp. 525-532). Dordrecht, The Netherlands: Springer Academic Publishers.

de Souza, M. (2008). Spirituality in Education: Addressing the inner and outer lives of students to promote meaning and connectedness in learning. In M. de Souza and W. Wing Han Lamb (Eds). Children, adolescents and spirituality. Interface. A Forum for Theology in the World, (pp. 98-118). Adelaide, South Australia: ATF Press.

de Souza, M. (2006). Rediscovering the spiritual dimension in education: promoting a sense of self and place, meaning and purpose in learning, In M. de Souza, K. Engebretson, G. Durka, R. Jackson, A. McGrady, (Eds). International handbook of the religious, moral and spiritual dimensions of education, (pp. 1127-1140). Dordrecht, The Netherlands: Springer Academic Publishers.

de Souza, M. (2003) Contemporary influences on the spirituality of young people: Implications for education. International Journal of Children's Spirituality, 18(3), 269-279.

de Souza, M., Cartwright, P., \& McGilp, E.J. (2004). The perceptions of young people who live in a regional city in Australia of their spiritual wellbeing: Implications for education. Journal of Youth Studies, 7(2), 155-172.

de Souza, M., Bone, J. \& Watson, J. (in press for 2016). Spirituality across disciplines: Research and practice. Dordrecht, The Netherlands: Springer Academic Publishers.

Einstein, A. Imagination is more important than knowledge. Retrieved on April 4, 2016, from http:/quoteinvestigator.com/2013/01/01/einstein-imagination/

Erricker, C. (2008). In fifty years, who will be here? Reflections on globalization, migration and spiritual identity. International Journal of Childrens' Spirituality 13(1), $15-26$.

Freire, P. (1970). Pedagogy of the oppressed. London: Penguin Books.

Gilbert, P. (2009). The compassionate mind: How to use compassion to develop happiness, self-acceptance and well-being. London: Constable and Robinson Ltd.

Mission Australia (2014). Youth mental health report 2014. Mission Australia in Association with the Black Dog Institute. Retrieved on July 6, 2015, from 
https://www.missionaustralia.com.au/component/search/?searchword=mental\% 20health\%20report\&searchphrase=all

Hay, D. (2006). Something there: The biology of the human spirit. London: Dartman, Longman \& Todd Ltd.

Hay, D. \& Nye, R. (1998). The spirit of the child. London: Found Paperbacks.

Helms, J. E. (1990/1993). Cultural racism: Conceptualization. American Psychology Association Division 38. Retrieved on May 7, 2014, from http://www.healthpsych.org/Cultural.cfm

hooks, b. (1994). Teaching to transgress. London: Routledge.

Hyde, B. (2008). Children and spirituality: Searching for meaning and connectedness. London: Jessica Kingsley Publishers.

Fisher, J. (2010). Reaching the heart: Assessing and nurturing spiritual well-being via education. Melbourne: Custom Book Centre, University of Melbourne.

Iliško, D., Skrinda, A. \& Mičule, I. (2014). Envisioning the future: Bachelor's and Master's degree students' perspectives. Journal of Teacher Education for Sustainability, 16 (2), 88-102. DOI: 10.2478/jtes-2014-0013.

Illich, I. (1970). Deschooling society. Middlesex: Penguin Books Ltd.

Lucas, B. \& Claxton, G. (2010). New kinds of smart: How the science of learnable intelligence is changing education. Berkshire, England: McGraw-Hill Education, Open University Press.

Miller, J. (2006). Educating for wisdom and compassion: Creating conditions for timeless learning. California: Corwin Press.

Miller, J. (2000). Education and soul: Towards a spiritual curriculum. Albany: State University of New York Press.

Miller, J. \& Nakagawa, Y. (Eds) (2001). Nurturing our wholeness: Perspectives on spirituality in education. Brandon, VT: Foundation for Educational Renewal.

Moffett, J. (1994). The universal schoolhouse. San Francisco: Jossey-Bass Inc.

Myers, D.G. (2002). Intuition: Its powers and perils. New Haven and London: Yale University Press.

Newberg, A., D’Aquili, E. \& Rause, V. (2001). Why God won't go away. New York: Ballantine Books.

Noddings, N. (1992). The challenge to care in schools. New York: Teacher's College Press.

Pinker, S. (2014). The village effect: Why face-to-face contact matters. London: Atlantic Books.

Pratt, D. (2015). Islamophobia as reactive co-radicalization. Islam and Christian-Muslim Relations, 26(2), 205-218, doi: 10.1080/09596410.2014.1000025

Robinson, K. (2001). Out of our minds: Learning to be creative. Chichester, West Sussex: Capstone Publishing Limited.

Robinson, K. \& Aronica, L. (2009). The element: How finding your passion changes everything. Victoria, Australia: Penguin Books.

Roy, O. (2004). Globalised Islam. The search for a new ummah. London: Hurst \& Company.

Tsiolkas, C. (2008). Tolerance, prejudice and fear: Sydney pen voices - the three writers' project. Crows Nest, New South Wales: Allen 7 Unwin.

Turkle, S. (2011). Alone together: Why we expect more from technology and less from each other. New York: Basic Books. 
Wilson, T. (2002). Strangers to ourselves: Discovering the adaptive unconscious. Cambridge, Massachusetts and London, England: The Belknap Press of Harvard University Press.

Correspondence concerning this article may be addressed to Dr Marian de Souza, Chair International Association for Children's Spirituality, Honorary Associate Professor, Faculty of Education and Arts, Federation University, Australia and Honorary Research Fellow, Australian Catholic University. Email: marian.desouza@bigpond.com.au 